Washington University School of Medicine Digital Commons@Becker

\title{
Epidemiology of methicillin-resistant Staphylococcus aureus colonization in a surgical intensive care unit
}

\author{
David K. Warren \\ Washington University School of Medicine in St. Louis \\ Rebecca M. Guth \\ Washington University School of Medicine in St. Louis \\ Craig M. Coopersmith \\ Washington University School of Medicine in St. Louis \\ Liana R. Merz \\ Washington University School of Medicine in St. Louis \\ Jeanne E. Zack \\ Missouri Baptist Medical Center
}

See next page for additional authors

Follow this and additional works at: https://digitalcommons.wustl.edu/open_access_pubs

Part of the Medicine and Health Sciences Commons

Please let us know how this document benefits you.

\section{Recommended Citation}

Warren, David K.; Guth, Rebecca M.; Coopersmith, Craig M.; Merz, Liana R.; Zack, Jeanne E.; and Fraser, Victoria J., "Epidemiology of methicillin-resistant Staphylococcus aureus colonization in a surgical intensive care unit." Infection Control and Hospital Epidemiology. 27, 10. 1032-1040. (2006).

https://digitalcommons.wustl.edu/open_access_pubs/884

This Open Access Publication is brought to you for free and open access by Digital Commons@Becker. It has been accepted for inclusion in Open Access Publications by an authorized administrator of Digital Commons@Becker. For more information, please contact vanam@wustl.edu. 


\section{Authors}

David K. Warren, Rebecca M. Guth, Craig M. Coopersmith, Liana R. Merz, Jeanne E. Zack, and Victoria J. Fraser 


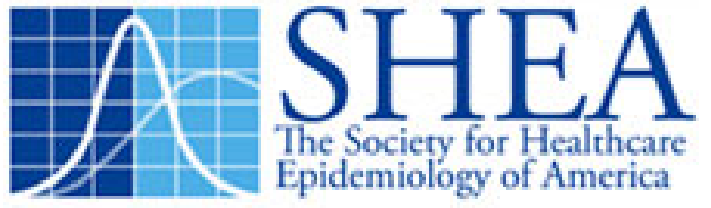

Epidemiology of Methicillin-Resistant Staphylococcus aureus Colonization in a Surgical Intensive Care Unit •

Author(s): David K. Warren , MD, MPH, Rebecca M. Guth, RRT, MPH, Craig M.

Coopersmith, MD, Liana R. Merz, MPH, Jeanne E. Zack, RN, BSN, CIC, Victoria J.

Fraser , MD

Reviewed work(s):

Source: Infection Control and Hospital Epidemiology, Vol. 27, No. 10 (October 2006), pp. 10321040

Published by: The University of Chicago Press on behalf of The Society for Healthcare Epidemiology of

America

Stable URL: http://www.jstor.org/stable/10.1086/507919

Accessed: $1 2 \longdiv { / 0 4 / 2 0 1 2 2 2 : 3 8 }$

Your use of the JSTOR archive indicates your acceptance of the Terms \& Conditions of Use, available at http://www.jstor.org/page/info/about/policies/terms.jsp

JSTOR is a not-for-profit service that helps scholars, researchers, and students discover, use, and build upon a wide range of content in a trusted digital archive. We use information technology and tools to increase productivity and facilitate new forms of scholarship. For more information about JSTOR, please contact support@jstor.org. 
INFECTION CONTROL AND HOSPITAL EPIDEMIOLOGY OCTOBER 2006, Vol. 27, No. 10

O R I G I N A L A R T I C L E

\title{
Epidemiology of Methicillin-Resistant Staphylococcus aureus Colonization in a Surgical Intensive Care Unit
}

\author{
David K. Warren, MD, MPH; Rebecca M. Guth, RRT, MPH; Craig M. Coopersmith, MD; Liana R. Merz, MPH; \\ Jeanne E. Zack, RN, BSN, CIC; Victoria J. Fraser, MD
}

\begin{abstract}
B ACKGROUND. Methicillin-resistant Staphylococcus aureus (MRSA) is a cause of healthcare-associated infections among surgical intensive care unit (ICU) patients, though transmission dynamics are unclear.

овJестіVе. To determine the prevalence of MRSA nasal colonization at ICU admission, to identify associated independent risk factors, to determine the value of these factors in active surveillance, and to determine the incidence of and risk factors associated with MRSA acquisition.
\end{abstract}

DESIgN. Prospective cohort study.

Setting. Surgical ICU at a teaching hospital.

Patients. All patients admitted to the surgical ICU.

RESUlTs. Active surveillance for MRSA by nasal culture was performed at ICU admission during a 15-month period. Patients who stayed in the ICU for more than 48 hours had nasal cultures performed weekly and at discharge from the ICU, and clinical data were collected prospectively. Of 1,469 patients, 122 (8\%) were colonized with MRSA at admission; 75 (61\%) were identified by surveillance alone. Among 775 patients who stayed in the ICU for more than 48 hours, risk factors for MRSA colonization at admission included the following: hospital admission in the past year (1-2 admissions: adjusted odds ratio [aOR], 2.60 [95\% confidence interval $\{\mathrm{CI}\}, 1.47-4.60]$; more than 2 admissions: aOR, 3.56 [95\% CI, 1.72-7.40]), a hospital stay of 5 days or more prior to ICU admission (aOR, 2.54 [95\% CI, 1.49-4.32]), chronic obstructive pulmonary disease (aOR, 2.16 [95\% CI, 1.17-3.96]), diabetes mellitus (aOR, 1.87 [95\% CI, 1.10-3.19]), and isolation of MRSA in the past 6 months (aOR, 8.18 [95\% CI, 3.38-19.79]). Sixty-nine (10\%) of 670 initially MRSA-negative patients acquired MRSA in the ICU (corresponding to 10.7 cases per 1,000 ICU-days at risk). Risk factors for MRSA acquisition included tracheostomy in the ICU (aOR, 2.18 [95\% CI, 1.13-4.20]); decubitus ulcer (aOR, 1.72 [95\% CI, 0.97-3.06]), and receipt of enteral nutrition via nasoenteric tube (aOR, 3.73 [95\% CI, 1.86-7.51]), percutaneous tube (aOR, 2.35 [95\% CI, 0.74-7.49]), or both (aOR, 3.33 [95\% CI, 1.13-9.77]).

CONCLUSIONS. Active surveillance detected a sizable proportion of MRSA-colonized patients not identified by clinical culture. MRSA colonization on admission was associated with recent healthcare contact and underlying disease. Acquisition was associated with potentially modifiable processes of care.

Infect Control Hosp Epidemiol 2006; 27:1032-1040

Staphylococcus aureus is one of the most frequent causes of nosocomial infection in intensive care unit (ICU) patients. ${ }^{1}$ The proportion of $S$. aureus isolates with methicillin resistance is increasing in both the United States and several European countries. ${ }^{2,3}$ Nasal colonization with $S$. aureus predisposes to subsequent infection, particularly in surgical patients. ${ }^{4-6}$ Infections caused by methicillin-resistant S. aureus (MRSA) have been associated with increased mortality and hospital costs, compared with methicillin-susceptible strains. ${ }^{7-9}$

Unidentified MRSA carriers serve as a potential reservoir for transmission. ${ }^{10}$ Active surveillance for MRSA, using screening cultures and aggressive contact precautions, has been shown to reduce MRSA transmission. ${ }^{10-12}$ The use of active surveillance helps in the determination of the prevalence and incidence of MRSA colonization in a given area or institution, though some studies have had incomplete data for admission screening cultures, ${ }^{13,14}$ potentially leading to biased estimates of these values. In addition, screening of all patients may be an overwhelming and costly task. Screening of patients at high-risk and those with known risk factors for MRSA colonization may be more feasible. Selective screening of patients for MRSA, combined with aggressive infection control measures, has been demonstrated to be an effective and cost-effective method to reduce MRSA transmission. ${ }^{11,12,15,16}$ However, selective screen-

From the Division of Infectious Diseases (D.K.W., V.J.F., R.M.G., L.R.M.) and the Departments of Surgery and Anesthesiology (C.M.C.), Washington University School of Medicine, Barnes Jewish Hospital (D.K.W., V.J.F.) and Missouri Baptist Medical Center, (J.E.Z.), Saint Louis, Missouri.

Received February 25, 2006; accepted May 19, 2006; electronically published August 31, 2006.

(C) 2006 by The Society for Healthcare Epidemiology of America. All rights reserved. 0899-823X/2006/2710-0006\$15.00. 
ing methods are often chosen on the basis of generalized risk factors rather than identified patient-specific risk factors in a given patient population.

The purpose of this study was to implement active surveillance for MRSA in a surgical ICU and to obtain high capture rates for admission surveillance cultures in order to accurately determine the prevalence of MRSA nasal colonization at ICU admission. Independent risk factors associated with MRSA colonization on admission were also ascertained, and the predictive value of the multivariate model was determined to assess the value of these factors as a screening tool for future active surveillance. In addition, we sought to determine the incidence of and risk factors associated with MRSA acquisition.

\section{METHODS}

This was a 15-month prospective cohort study conducted from December 2002 through February 2004 in the surgical ICU at Barnes-Jewish Hospital (BJH). BJH is a 1,251-bed, urban, tertiary care teaching hospital in St. Louis, Missouri. The burn, trauma, and surgical ICU has 24 beds and approximately 1,400 admissions per year.

MRSA active surveillance was instituted in the surgical ICU by the hospital infection control department in December 2002. Nasal culture for S. aureus was performed for all patients admitted to the ICU who stayed for more than 12 hours. Nasal swab specimens for culture were also obtained weekly and at discharge from the ICU for all patients who stayed in the ICU for more than 48 hours. A specimen was collected from both anterior nares of each patient. Collected specimens were transported and stored at room temperature. Mannitol salt agar plates (Becton Dickinson) were inoculated directly with swab specimens. The mannitol salt agar plates were incubated for $24-48$ hours at $35^{\circ} \mathrm{C}$ and examined for growth. Strains that produced yellow colonies on the screening mannitol salt agar plates were confirmed as $S$. aureus by means of Gram staining, 3\% catalase testing, and coagulase testing with the Staph Latex agglutination assay (LifeSign). Detection of MRSA was performed by subculturing confirmed S. aureus isolates in Trypase soy broth with 5\% sheep blood (Becton Dickinson), then on oxacillin screening agar containing 6.0 $\mu \mathrm{g} / \mathrm{mL}$ of oxacillin (Becton Dickinson). Plates were incubated at $35^{\circ} \mathrm{C}$ for $18-24$ hours and examined for evidence of growth. Strains showing distinct growth were considered to be methicillin resistant.

Data collected for all study patients included demographic characteristics, hospital and ICU admission dates, admission to $\mathrm{BJH}$ in the past 12 months, location prior to hospital admission (ie, home, another hospital, or a long-term care facility), use of contact precautions, and hospital and ICU discharge dates and discharge status. Additional data were collected for patients who remained in the ICU for more than 48 hours, including past medical history, ICU processes of care and medications received, and use of mechanical ventilation and/or central venous catheters. Each nasoenteric tube used was identified as a nasogastric or Dobhoff tube. Each percutaneous feeding tube was defined as a gastrostomy, jejunostomy, or gastrojejunostomy tube. In accordance with hospital policy, patients found to be colonized or infected with MRSA, vancomycin-resistant enterococci (VRE), Clostridium difficile (associated with diarrhea), and certain multidrug-resistant, gram-negative bacilli were placed under contact precautions. In addition, patients with a history of colonization with these organisms were identified and placed under contact precautions at admission. Decolonization therapy for MRSA was not routinely done. All positive clinical culture results and ICU-related infections were recorded. Infections were defined using the National Nosocomial Infection Surveillance system criteria. $^{17}$

MRSA colonization at admission was defined as an admission nasal surveillance culture positive for MRSA or any clinical culture positive for MRSA within 48 hours after ICU admission. MRSA acquisition was defined as an admission nasal surveillance culture negative for MRSA and subsequent isolation of MRSA from a surveillance or clinical culture performed more than 48 hours after admission. Incidence density was calculated as the number of cases of MRSA acquisition per 1,000 total patient-days and per 1,000 days at risk for MRSA colonization (ie, days on which a given patient had no MRSA detected). At-risk ICU-days were calculated by excluding from the denominator the ICU-days of patients colonized with MRSA on admission, and only including patient-days occurring prior to MRSA colonization for those acquiring MRSA in the ICU.

Statistical analysis was performed using SPSS for Windows, version 12.0 (SPSS). Sensitivity, specificity, and positive and negative predictive values were all calculated using standard methodology. ${ }^{18}$ Categorical variables were analyzed using the $\chi^{2}$ test or Fisher's exact test, as appropriate, and analysis of continuous variables was performed using the Wilcoxon rank-sum test. Two-tailed tests were used, and $P<.05$ was considered statistically significant. Previously known risk factors or clinically relevant significant variables from the univariate analysis were considered for inclusion in multivariate logistic regression analysis. Backward stepwise logistic regression was performed, and the model that was considered biologically plausible and had the lowest -2 log likelihood ratio was chosen as the final model. Variables were tested for first-order interaction effects, and none were noted. The Hosmer and Lemeshow goodness-of-fit test was used to assess model fit. The Washington University Institutional Review Board approved this study.

\section{RES ULT S}

During the study period, 1,469 (98\%) of 1,494 patients admitted to the ICU had an admission nasal culture performed. 
TABLE 1. Demographic Characteristics of 775 Patients Who Stayed in the Surgical Intensive Care Unit (ICU) for More Than 48 Hours for Whom a Nasal Swab Specimen Was Obtained at Admission

\begin{tabular}{|c|c|}
\hline Variable & Value \\
\hline \multicolumn{2}{|l|}{ Baseline patient characteristics } \\
\hline Male sex & $458(59)$ \\
\hline \multicolumn{2}{|l|}{ Age in years } \\
\hline Median (range) & $60(17-97)$ \\
\hline Mean & 58 \\
\hline White race & $585(76)$ \\
\hline Contact precautions at time of ICU admission & $82(11)$ \\
\hline \multicolumn{2}{|l|}{ Admission to $\mathrm{BJH}$ in past 12 months } \\
\hline None & $539(70)$ \\
\hline 1-2 admissions & $170(22)$ \\
\hline$>2$ admissions & $66(8)$ \\
\hline \multicolumn{2}{|l|}{ Location prior to hospital admission } \\
\hline Home & $608(78)$ \\
\hline Long-term care facility & $21(3)$ \\
\hline Other hospital & $146(19)$ \\
\hline \multicolumn{2}{|l|}{ Pre-ICU LOS in days } \\
\hline Median (range) & $0(0-143)$ \\
\hline Mean & 4 \\
\hline \multicolumn{2}{|l|}{ Conditions present at admission } \\
\hline Congestive heart failure & $79(10)$ \\
\hline COPD & $106(14)$ \\
\hline Malignancy (current diagnosis) & $129(17)$ \\
\hline Chemotherapy (in the past 28 days) & $11(1)$ \\
\hline Chronic skin disease & $8(1)$ \\
\hline Diabetes mellitus & $187(24)$ \\
\hline Systemic corticosteroid use (in the past 28 days) & $58(8)$ \\
\hline \multicolumn{2}{|l|}{ Baseline renal function } \\
\hline Normal & $690(89)$ \\
\hline Chronic renal failure & $58(8)$ \\
\hline Chronic renal failure with dialysis & $27(4)$ \\
\hline Cirrhosis & $36(5)$ \\
\hline Solid organ or bone marrow transplant & $15(2)$ \\
\hline \multicolumn{2}{|l|}{ Surgical procedure } \\
\hline Prior to admission (within past 3 months) & $150(19)$ \\
\hline Current hospitalization & $633(82)$ \\
\hline Burn patient & $11(1)$ \\
\hline \multicolumn{2}{|l|}{ Antibiotic use and resistant organisms } \\
\hline MRSA isolated in past 6 months & $29(4)$ \\
\hline Any infection in past 3 months & $143(18)$ \\
\hline Antibiotic use in past 3 months & $160(21)$ \\
\hline C. difficile-associated diarrhea in past 3 months & $19(2)$ \\
\hline VRE isolated in past 3 months & $38(5)$ \\
\hline MRSA colonized on admission & $82(11)$ \\
\hline \multicolumn{2}{|l|}{ ICU-related events } \\
\hline \multicolumn{2}{|l|}{ Tracheostomy } \\
\hline None & $585(76)$ \\
\hline Present on admission to ICU & $27(3)$ \\
\hline Performed while in ICU & $163(21)$ \\
\hline Decubitus ulcer in ICU & $171(22)$ \\
\hline \multicolumn{2}{|l|}{$\mathrm{CVC}$} \\
\hline Present & $539(71)$ \\
\hline Duration, median total CVC-days (range) & $7(0-63)$ \\
\hline
\end{tabular}

TABLE 1. (Continued)

\begin{tabular}{lc}
\hline Variable & Value \\
\hline Mechanical ventilation & $592(76)$ \\
Received & $4(0-66)$ \\
Median ventilator-days (range) & $85(11)$ \\
Reintubation & $73(9)$ \\
Systemic corticosteroid use & $41(5)$ \\
Antacid use & $667(86)$ \\
$\mathrm{H}_{2}$ antagonist use & $7(1)$ \\
Sucralfate use & $299(39)$ \\
Vasopressor use & \\
Enteral nutrition & $483(62)$ \\
None & $212(27)$ \\
Via nasoenteric tube & $43(6)$ \\
Via percutaneous tube & \\
Via nasoenteric and percutaneous tube & $37(5)$ \\
Total parenteral nutrition & $224(29)$ \\
Outcomes & $6(3-76)$ \\
Median ICU LOS in days (range) & $19(4-219)$ \\
Median hospital LOS in days (range) & \\
Hospital discharge status & $109(14)$ \\
Death & $349(45)$ \\
Discharged home & $277(36)$ \\
Discharged to LTC facility & $40(5)$ \\
Discharged to other hospital & \\
\hline
\end{tabular}

Nоте. Data are no. (\%) of patients, unless otherwise specified. BJH, Barnes-Jewish Hospital; COPD, chronic obstructive pulmonary disease; CVC, central venous catheter; LOS, length of stay, LTC, long-term care; MRSA, methicillin-resistant Staphylococcus aureus; VRE, vancomycin-resistant enterococci.

${ }^{a}$ Nasoenteric tube includes nasogastric tubes and Dobhoff tubes.

b Percutaneous tube includes gastrostomy, jejunostomy, and gastrojejunostomy tubes.

Of those from whom a nasal swab specimen was obtained, $122(8 \%)$ were colonized with MRSA on admission to the ICU. Of these 122 patients, 75 (61\%) had MRSA colonization detected by surveillance culture alone while they were in the ICU. Two patients (2\%) had MRSA colonization detected by clinical culture alone.

Risk factor analysis was performed only for the 775 (53\%) patients who stayed in the ICU for more than 48 hours and had a nasal swab specimen obtained at admission (Table 1). The median age of admitted patients was 60 years (range, 17-97 years), and 458 (59\%) were male. Eighty-two (11\%) of 775 patients who stayed in the ICU more than 48 hours were colonized with MRSA (Table 2). Patients with MRSA colonization on admission were likely to have had recent healthcare contact, defined as admission to $\mathrm{BJH}$ in the past year, admission from a long-term care facility or from another hospital, or a pre-ICU hospital length of stay of at least 5 days, compared with patients who were not colonized on admission ( $85 \%$ vs $52 \%, P<.001)$. On multivariate testing, factors independently associated with MRSA colonization on 
TABLE 2. Comparison of Patients With and Patients Without Methicillin-Resistant Staphylococcus aureus (MRSA) Colonization on Admission to the Surgical Intensive Care Unit (ICU)

\begin{tabular}{|c|c|c|c|c|}
\hline \multirow[b]{2}{*}{ Variable } & \multicolumn{3}{|c|}{ Univariate analysis, value } & \multirow[b]{2}{*}{$\begin{array}{l}\text { Multivariate } \\
\text { analysis: aOR } \\
(95 \% \mathrm{CI})\end{array}$} \\
\hline & $\begin{array}{c}\text { Patients } \\
\text { with MRSA } \\
(n=693)\end{array}$ & $\begin{array}{c}\text { Patients } \\
\text { without MRSA } \\
\quad(n=82)\end{array}$ & $P$ & \\
\hline Male & $408(59)$ & $50(61)$ & .714 & \\
\hline Median age in years (range) & $59(17-97)$ & $67(23-96)$ & .008 & \\
\hline Race (white) & $520(75)$ & $65(79)$ & .400 & \\
\hline \multicolumn{5}{|l|}{ Admission to $\mathrm{BJH}$ in past 12 months } \\
\hline None & $507(73)$ & $32(39)$ & $\operatorname{Ref}^{b, c}$ & Ref \\
\hline 1-2 admissions & $140(20)$ & $30(37)$ & $<.001$ & $2.60(1.47-4.60)$ \\
\hline$>2$ admissions & $46(7)$ & $20(24)$ & $<.001$ & $3.56(1.72-7.40)$ \\
\hline \multicolumn{5}{|l|}{ Location prior to hospital admission } \\
\hline Home & $552(80)$ & $56(68)$ & $\operatorname{Ref}^{\mathrm{b}}$ & \\
\hline Long-term care facility & $13(2)$ & $8(10)$ & $<.001$ & \\
\hline Other hospital & $128(18)$ & $18(22)$ & .257 & \\
\hline Pre-ICU LOS of $\geqslant 5$ days & $132(19)$ & $36(44)$ & $<.001$ & $2.54(1.49-4.32)$ \\
\hline \multicolumn{5}{|l|}{ Conditions present at admission } \\
\hline Congestive heart failure & $63(9)$ & $16(20)$ & .003 & \\
\hline COPD & $84(12)$ & $22(27)$ & $<.001$ & $2.16(1.17-3.96)$ \\
\hline Malignancy (current diagnosis) & $114(16)$ & $15(18)$ & 672 & \\
\hline Chemotherapy (in the past 28 days) & $8(1)$ & $3(4)$ & .101 & \\
\hline Chronic skin disease & $7(1)$ & $1(1)$ & .593 & \\
\hline Diabetes mellitus & $152(22)$ & $35(43)$ & $<.001$ & $1.87(1.10-3.19)$ \\
\hline Systemic corticosteroid use (in the past 28 days) & $49(7)$ & $9(11)$ & .204 & \\
\hline \multicolumn{5}{|l|}{ Baseline renal function } \\
\hline Normal & $623(90)$ & $67(82)$ & $\operatorname{Ref}^{b}$ & \\
\hline CRF & $45(6)$ & $13(16)$ & .004 & \\
\hline CRF with dialysis & $25(4)$ & $2(2)$ & .692 & \\
\hline Cirrhosis & $32(5)$ & $4(5)$ & .786 & \\
\hline Solid organ or bone marrow transplant & $14(2)$ & $1(1)$ & 1.0 & \\
\hline \multicolumn{5}{|l|}{ Surgical procedure } \\
\hline Prior to admission (in the past 90 days) & $120(17)$ & $30(37)$ & $<.001$ & \\
\hline During current ICU stay & $562(81)$ & $71(87)$ & .224 & \\
\hline Burn patient & $11(2)$ & $0(0)$ & .617 & \\
\hline Tracheostomy present at admission & $20(3)$ & $7(8)$ & .018 & \\
\hline \multicolumn{5}{|l|}{ Antibiotic use and resistant organisms } \\
\hline MRSA isolated in past 6 months & $11(2)$ & $18(22)$ & $<.001$ & $8.18(3.38-19.79)$ \\
\hline Any infection in past 3 months & $108(16)$ & $35(43)$ & $<.001$ & \\
\hline Antibiotic use in past 3 months & $125(18)$ & $35(43)$ & $<.001$ & \\
\hline C. difficile-associated diarrhea in past 3 months & $11(2)$ & $8(10)$ & $<.001$ & \\
\hline VRE isolated in past 3 months & $26(4)$ & $12(15)$ & $<.001$ & \\
\hline
\end{tabular}

NOTE. Data are no. (\%) of patients, unless otherwise specified. aOR, adjusted odds ratio; BJH, Barnes-Jewish Hospital; $C$. difficile, Clostridium difficile; COPD, chronic obstructive pulmonary disease; CRF, chronic renal failure; LOS, length of stay; Ref, reference category; VRE, vancomycin-resistant enterococci.

a Other variables considered for inclusion into the final model: admission from a long-term care facility, infection in the past 3 months, antibiotic use in past 3 months, $C$. difficile-associated diarrhea in past 3 months, VRE colonization in past 3 months, and surgical procedure in the 3 months prior to admission.

${ }^{\mathrm{b}}$ Obtained from univariate logistic regression analysis.

${ }^{c} \chi^{2}$ for trend, 48.31; $P<.001$.

admission were as follows: 1 or 2 admissions to $\mathrm{BJH}$ in the past year (adjusted odds ratio [aOR], 2.60 [95\% confidence interval $\{\mathrm{CI}\}, 1.47-4.60]$ ), more than 2 admissions to $\mathrm{BJH}$ in the past year (aOR, 3.56; 95\% CI, 1.72-7.40]), a hospital length of stay of 5 days or more prior to admission to the surgical ICU (aOR, 2.54 [95\% CI, 1.49-4.32]), chronic ob- structive pulmonary disease (aOR, 2.16 [95\% CI, 1.17-3.96), diabetes mellitus (aOR, 1.87 [95\% CI, 1.10-3.19), and isolation of MRSA in the past 6 months (aOR, 8.18 [95\% CI, 3.38-19.79]) (Table 2).

The predictive ability of the model to detect MRSA colonization on admission in patients who stayed in the ICU 
TABLE 3. Sensitivity and Specificity of Independent Risk Factor Variables for Prediction of Methicillin-Resistant Staphylococcus aureus (MRSA) Colonization Among Patients Who Stayed in the Surgical Intensive Care Unit (ICU) for More Than 48 Hours

\begin{tabular}{lccc}
\hline Variable & $\begin{array}{c}\text { Sensitivity, } \\
\%\end{array}$ & $\begin{array}{c}\text { Specificity, } \\
\%\end{array}$ & $\begin{array}{c}\text { Percentage of } \\
\text { patients admitted } \\
\text { to ICU }\end{array}$ \\
\hline One predictor variable & & & \\
A: Admission to BJH in past year & 61 & 73 & 30 \\
B: Pre-ICU LOS of $\geqslant 5$ days & 44 & 81 & 22 \\
C: MRSA isolated in the past 6 months & 22 & 98 & 4 \\
D: Chronic obstructive pulmonary disease & 27 & 88 & 14 \\
E: Diabetes mellitus & 43 & 78 & 24 \\
Predictor variable A, B, or C & 79 & 61 & 43 \\
Any predictor variable & 89 & 45 & 58 \\
\hline
\end{tabular}

Note. BJH, Barnes-Jewish Hospital; LOS, length of stay.

for more than 48 hours is shown in Table 3. Presence of at least 1 of the independent risk factors had a sensitivity of $89 \%$ and a specificity of $45 \%$ for identification of a patient with MRSA colonization on admission. Use of the risk factors as a screening tool for active surveillance would lower the percentage of ICU patients from whom admission surveillance swab specimens were required to $58 \%$. In this cohort, the positive predictive value of this screening method was $16 \%$, and the negative predictive value was $97 \%$.

Of the 693 patients who were initially culture negative for MRSA and who remained in the ICU for more than 48 hours, $669(97 \%)$ had at least 1 follow-up nasal surveillance culture performed (range, 1-10 cultures). One additional patient did not have a follow-up nasal culture performed but was found to be MRSA positive by routine clinical culture and was included in the analysis (Figure). Sixty-nine patients (10\%) were newly colonized with MRSA on follow-up ( 9.5 cases per 1,000 ICU-days; 10.7 cases per 1,000 patient-days at risk). The median time to culture positivity was 8 days (range, 2-24 days). Twenty-seven (39\%) of 69 patients were identified by surveillance culture alone, and another 5 (7\%) were detected by routine clinical culture alone. The time from the culture date (ie, the date the swab specimen for culture was obtained) to the availability of results was a median of 3 days. Of the patients who acquired MRSA, 16 (23\%) developed an MRSA infection during their ICU stay (8 bloodstream infections, 3 cases of ventilator-associated pneumonia, and 5 other infections [eg, intra-abdominal abscess, surgical site infection, or pneumonia]).

Risk factors associated with acquisition of MRSA in the surgical ICU on univariate analysis are shown in Table 4. Risk factors included in the final multivariate model were tracheostomy in the ICU (aOR, 2.18 [95\% CI, 1.13-4.20]), development of a decubitus ulcer while in the ICU (aOR, 1.72 [95\% $\mathrm{CI}, 0.97-3.06])$, and enteral nutrition via nasoenteric tube (aOR, 3.51 [95\% CI, 1.74 to 7.07]), via percutaneous feeding tube (aOR, 2.35 [95\% CI, 0.74-7.49]), or both nasoenteric and percutaneous tube (aOR, 3.33 [95\% CI, 1.13-9.77]) (Table 4). The presence of decubitus ulcers was retained in the multi- variate model, even though the $P$ value was greater than .05 , because the aORs of the other variables changed more than $10 \%$ when the risk factor was removed from the model.

\section{I S C USS I ON}

Multiple studies have performed active surveillance for MRSA and examined risk factors associated with MRSA colonization, though few have achieved the extremely high initial surveillance culture capture rates achieved in this study population. Nasal specimens for surveillance culture were obtained from $98 \%$ of all patients admitted to the ICU in this study, increasing the validity of the MRSA prevalence estimate. Eight percent of all patients admitted to this ICU were already colonized with MRSA. Other ICU populations have reported admission prevalence rates of $4 \%-9 \% .^{12-14,19}$ Of the patients colonized with MRSA on admission, $61 \%$ never had an MRSA-positive clinical culture during their ICU stay.

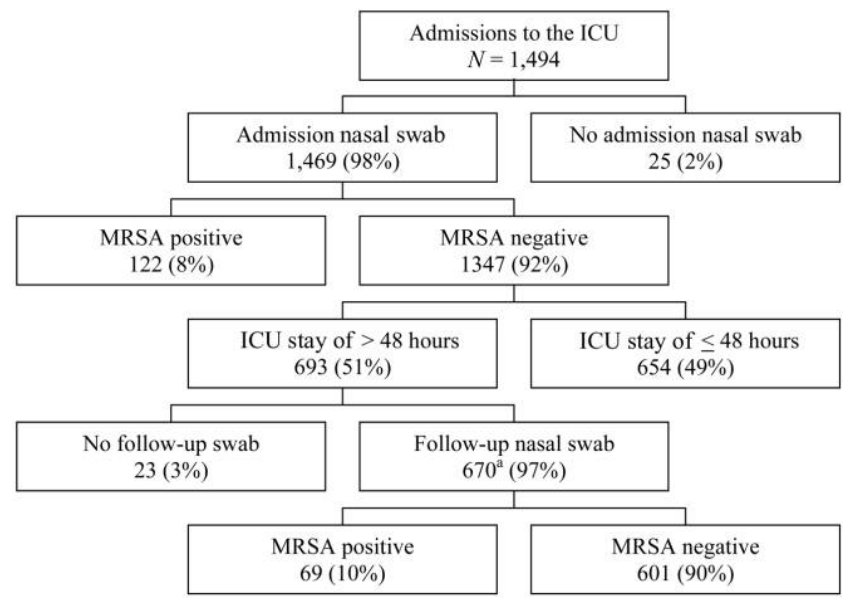

FIGURE Distribution of the study population. Data are no. (\%) of patients. ICU, intensive care unit, MRSA, methicillin-resistant Staphylococcus aureus. ${ }^{a}$ One patient did not have a follow-up nasal swab specimen obtained but was determined to be MRSA positive by clinical culture and was included in the analysis. 
TABLE 4. Analysis of Risk Factors and Outcomes Associated With Acquisition of Methicillin-Resistant Staphylococcus aureus (MRSA) During Surgical Intensive Care Unit Stay

\begin{tabular}{|c|c|c|c|c|}
\hline \multirow[b]{2}{*}{ Variable } & \multicolumn{3}{|c|}{ Univariate analysis, value } & \multirow[b]{2}{*}{$\begin{array}{c}\text { Multivariate } \\
\text { analysis: aOR } \\
(95 \% \text { CI })\end{array}$} \\
\hline & $\begin{array}{c}\text { Patients } \\
\text { with MRSA } \\
(n=601)\end{array}$ & $\begin{array}{c}\text { Patients } \\
\text { without MRSA } \\
(n=69)\end{array}$ & $P$ & \\
\hline \multicolumn{5}{|l|}{ Patient characteristics } \\
\hline Male sex & $353(59)$ & $41(59)$ & .913 & \\
\hline Age, median years (range) & $60(17-94)$ & $57(19-96)$ & .998 & \\
\hline White race & $453(75)$ & $48(70)$ & .293 & \\
\hline \multicolumn{5}{|l|}{ Conditions present at admission } \\
\hline Congestive heart failure & $52(9)$ & $11(16)$ & .049 & \\
\hline COPD & $68(11)$ & $14(20)$ & .031 & \\
\hline Malignancy (current diagnosis) & $105(18)$ & $7(10)$ & .122 & \\
\hline Chemotherapy (in the past 28 days) & $8(1)$ & $0(0)$ & 1.0 & \\
\hline Chronic skin disease & $6(1)$ & $1(1)$ & .534 & \\
\hline Diabetes mellitus & $126(21)$ & $21(30)$ & .072 & \\
\hline Systemic corticosteroid use (in the past 28 days) & $42(7)$ & $5(7)$ & 1.0 & \\
\hline \multicolumn{5}{|l|}{ Renal function } \\
\hline Normal & $540(90)$ & $62(90)$ & $\operatorname{Ref}^{\mathrm{b}}$ & \\
\hline CRF & $37(6)$ & $7(10)$ & .249 & \\
\hline CRF with dialysis & $24(4)$ & $0(0)$ & .998 & \\
\hline Cirrhosis & $32(5)$ & $0(0)$ & .065 & \\
\hline Solid organ or bone marrow transplant & $14(2)$ & $0(0)$ & .382 & \\
\hline \multicolumn{5}{|l|}{ Surgical procedure } \\
\hline Prior to admission (in the past 90 days) & $110(18)$ & $7(10)$ & .091 & \\
\hline Current admission & $486(81)$ & $63(91)$ & .033 & \\
\hline Burn patient & $9(2)$ & $1(1)$ & 1.0 & \\
\hline \multicolumn{5}{|l|}{ Antibiotic use and resistant organisms } \\
\hline MRSA isolated in past 6 months & $6(1)$ & $4(6)$ & .013 & \\
\hline Any infection in past 3 months & $91(15)$ & $12(17)$ & .599 & \\
\hline Antibiotic use in past 3 months & $112(19)$ & $9(13)$ & .253 & \\
\hline C. difficile-associated diarrhea in past 3 months & $11(2)$ & $0(0)$ & .615 & \\
\hline VRE isolated in past 3 months & $20(3)$ & $4(6)$ & .297 & \\
\hline \multicolumn{5}{|l|}{ ICU-related events } \\
\hline Tracheostomy performed while in ICU & $106(18)$ & $37(54)$ & $<.001$ & $2.18(1.13-4.20)$ \\
\hline Decubitus ulcer & $115(19)$ & $32(46)$ & $<.001$ & $1.72(0.97-3.06)^{\mathrm{c}}$ \\
\hline \multicolumn{5}{|l|}{$\mathrm{CVC}$} \\
\hline Present & $404(67)$ & $58(84)$ & .004 & \\
\hline Duration, median CVC-days (range) & $7(0-63)$ & $14(0-62)$ & $<.001$ & \\
\hline \multicolumn{5}{|l|}{ Mechanical ventilation } \\
\hline Received & $443(74)$ & $62(90)$ & .003 & \\
\hline Duration, median ventilator-days (range) & $3(0-66)$ & $15(0-60)$ & $<.001$ & \\
\hline Reintubation & $60(10)$ & $13(19)$ & .025 & \\
\hline Systemic corticosteroid use & $53(9)$ & $7(10)$ & .715 & \\
\hline Antacid use & $31(5)$ & $4(6)$ & .775 & \\
\hline $\mathrm{H}_{2}$ antagonist use & $515(86)$ & $62(90)$ & .343 & \\
\hline Sucralfate use & $6(1)$ & $0(0)$ & 1.0 & \\
\hline Vasopressor use & $206(34)$ & $40(58)$ & $<.001$ & \\
\hline \multicolumn{5}{|l|}{ Enteral nutrition } \\
\hline None & $400(67)$ & $17(25)$ & $\operatorname{Ref}^{\mathrm{b}}$ & Ref \\
\hline Via nasoenteric feeding tube & $148(25)$ & $38(55)$ & $<.001$ & $3.51(1.74-7.07)$ \\
\hline Via percutaneous feeding tube & $28(5)$ & $5(7)$ & .008 & $2.35(0.74-7.49)$ \\
\hline Via nasoenteric and percutaneous tube & $25(4)$ & $9(13)$ & .001 & $3.33(1.13-9.77)$ \\
\hline Total parenteral nutrition & $163(27)$ & $20(29)$ & .742 & \\
\hline \multicolumn{5}{|l|}{ Outcomes } \\
\hline Median ICU LOS in days (range) & $6(3-66)$ & $18(3-76)$ & $<.001$ & \\
\hline Median hospital LOS in days (range) & $18(4-219)$ & $28(7-96)$ & $<.001$ & \\
\hline Death during hospitalization & $65(11)$ & $14(20)$ & .021 & \\
\hline
\end{tabular}

nоте. Data are no. (\%) of patients, unless otherwise specified. aOR, adjusted odds ratio; C. difficile, Clostridium difficile; COPD, chronic obstructive pulmonary disease; CRF, chronic renal failure; CVC, central venous catheter; LOS, length of stay; Ref, reference category; VRE, vancomycin-resistant enterococci.

a Other variables considered for inclusion into the model: no. of CVC-days, no. of mechanical ventilation-days, and vasopressor use.

${ }^{\mathrm{b}}$ Obtained from univariate logistic regression.

${ }^{c}$ Retained in final model because of its confounding effect (see Methods). 
Other studies have found similar detection rates, with only $25 \%-60 \%$ of all MRSA-colonized patients detected by routine clinical culture. ${ }^{12,19-22}$ There is ongoing debate concerning the effectiveness of contact precautions to reduce transmission of MRSA or other antibiotic-resistant organisms. ${ }^{22}$ However, reliance on routine clinical cultures alone leaves many MRSA carriers undetected, which is likely to compromise the overall success of infection control measures.

Patients with a history of MRSA colonization in the previous 6 months were 8 times more likely to be colonized with MRSA on admission to the ICU. Estimates of long-term persistence of MRSA colonization vary widely, from several months to more than 3 years. ${ }^{23-26}$ Decolonization therapy, including intranasal mupirocin therapy and chlorhexidine baths, have been used with varying degrees of success to decrease the prevalence of long-term colonization. ${ }^{27}$ The efficacy of these methods depends on the antimicrobial agent, the body site, and whether MRSA is endemic in a particular setting. ${ }^{27}$ Future studies are planned in our ICU in which decolonization therapy will be implemented to reduce the prevalence of MRSA colonization.

Recent healthcare contact was a predominant risk factor associated with MRSA colonization on admission in the surgical ICU in this study, which is a common finding in other investigations. $^{12,19,20}$ Both previous admission to BJH and a hospital length of stay of 5 days or more prior to admission to the surgical ICU were associated with increased risk, which suggests ongoing institutional transmission of MRSA. Eightyfive percent of the patients colonized with MRSA on admission had had some form of recent healthcare contact (recent hospital admission, admission from a long-term care facility or from another hospital, or a hospital length of stay of 5 days or more prior to admission to the surgical ICU). However, $15 \%$ of patients colonized with MRSA at admission did not have some identifiable healthcare contact in the past year, which raises the possibility of community-acquired MRSA colonization. Without molecular typing of isolates for determinants associated with community-acquired MRSA, such as SCCmec type IV ${ }^{28}$ this cannot be proven at this time.

Patients with chronic diseases, such as COPD or diabetes mellitus, had a higher likelihood of MRSA colonization on admission. Diabetes has been identified as a risk factor for MRSA colonization at hospital admission, ${ }^{29}$ but COPD is generally not recognized as a common risk factor. Although it is controversial, antibiotic therapy is frequently prescribed for COPD exacerbations and may lead to increased antibiotic resistance in these patients. ${ }^{30}$ There was no difference in antibiotic use in the 3 months prior to admission between patients with and patients without COPD, which would argue against this explanation. However, there were limited data available to establish a patient's history of antibiotic use prior to hospital admission, and it is unlikely that information on all previous antibiotic use was captured, particularly antibiotic therapy received at other hospitals or through outpatient treatment.

Active screening of all patients on admission is labor- and resource intensive. Girou et al. ${ }^{12}$ found that selective screening for MRSA based on risk factors was as effective as screening all patients in detecting colonized patients, but this selective strategy was not determined to be a cost-effective strategy in a larger study. ${ }^{19}$ In our study, screening by significant predictor variables from multivariate analysis would identify $89 \%$ of MRSA colonized patients at admission and would decrease the total number of admission surveillance cultures required by $42 \%$, assuming that the group of all patients admitted to the ICU had the same frequency of risk factors as did the group who stayed in the ICU for more than 48 hours. Whether this approach would identify sufficient numbers of patients colonized with MRSA on admission to reduce transmission in this setting remains to be determined. Increased community-acquired MRSA may also alter the efficacy of such risk-based screening.

In this study, $10 \%$ of patients in the surgical ICU acquired MRSA. Estimates in the literature of rates of acquisition in an ICU vary from $4 \%$ to $11 \% .{ }^{12-14}$ The MRSA acquisition rate in our ICU was 10.7 cases per 1,000 ICU-days at-risk. This value reflects a more accurate estimate of incidence, as it accounts for length of stay in the ICU before the time of MRSA colonization, as opposed to including all ICU-days in the denominator. Others have used the total number of patient-days to calculate the incidence density of MRSA colonization, ${ }^{31,32}$ which would underestimate the true acquisition rate.

This study mainly focused on patient risk factors and processes of care associated with MRSA acquisition. All of the predictors in the multivariate model are indicators of increased severity of illness, which potentially raises the intensity of care and time of contact with healthcare professionals. MRSA colonization in wounds and skin ulcers is well documented. ${ }^{21,25,33}$ Microbial contamination of tube feeding solution has been associated with nosocomial infection. ${ }^{34}$ In this study, tube feeding via a percutaneous tube alone did not significantly elevate the risk of MRSA acquisition in the multivariate model, suggesting that the route was the risk factor, rather than tube feeding solution itself. Dziekan et al. ${ }^{35}$ identified the presence of a nasogastric tube as a risk factor for MRSA colonization, further supporting this theory. More research is needed to determine the impact of nasoenteric tubes on MRSA nasal colonization.

There are some limitations to this study. Because of logistical constraints, comorbidity and process of care data were collected only for patients who remained in the ICU for more than 48 hours; brief ICU stays may contribute to the transmission of MRSA but were not captured by this analysis. In addition, a severity-of-illness measure (eg, Acute Physiology and Chronic Health Evaluation II score) was not available for all patients for inclusion in risk factor analysis. However, surrogate markers, such as information on vasopressor use and use of mechanical ventilation, were available. Other information that could not be reliably ascertained for all subjects was admission to other healthcare facilities in the past 
year, which may have been a risk factor for MRSA colonization on admission.

Specimens for surveillance culture were only taken from the nares. The use of nasal cultures alone for the detection of MRSA colonization has a sensitivity of $78 \%-85 \%,{ }^{12,19,21}$ compared with use of surveillance cultures of specimens from multiple body sites. Therefore, several patients who were classified as having acquired MRSA may have already been colonized at admission. Four of 10 patients with a history of prior MRSA colonization were culture negative for MRSA on admission and were culture positive on subsequent followup testing, suggesting they were colonized with MRSA on admission. Performance of additional cultures of specimens from other body sites may increase the detection of MRSA carriage but would result in increased cost of surveillance. In addition, surveillance cultures were only performed weekly and at discharge, which may underestimate the overall incidence density. Finally, molecular typing of MRSA isolates would enhance our understanding of MRSA transmission in this population but was not feasible with current resources.

A significant number of patients admitted to the ICU in this study were colonized with MRSA. Sixty-one percent of MRSA-colonized patients identified by nasal culture on admission would not have been identified by routine clinical culture in the ICU. Risk factors for MRSA colonization on admission include recent colonization with MRSA, recent healthcare contact, and presence of an underlying illness, such as COPD, which is not a commonly identified risk factor. Another $10 \%$ of patients acquired MRSA despite infection control measures. Acquisition was associated with acuity of care and processes of care, including enteral feeding via nasoenteric tube. This important baseline data will facilitate future interventions necessary to limit MRSA transmission in this ICU.

Address reprint requests to David K. Warren, MD, MPH, Division of Infectious Diseases, Washington University School of Medicine, 660 South Euclid Avenue, Campus Box 8051, Saint Louis, MO 63110 (dwarren@ im.wustl.edu).

Presented in part: 14th Annual Meeting of the Society for Healthcare Epidemiology of America; April 2004; Philadelphia, PA; Abstract 175.

Potential conflict of interest: D.K.W. receives research support from GeneOhm Science.

\section{ACKNOWLEDGMENTS}

We gratefully acknowledge the following individuals who made this study possible: Ms. Sondra Seiler, for data collection; Ms. Cherie Hill, for data management; and Ms. Myrna Ward, Dr. Timothy Buchman, Dr. Walter Boyle, and the physician and nursing staff of the Barnes Jewish Hospital surgical intensive care unit, for support of this project.

Financial support was received from the Centers for Disease Control and Prevention (grant UR8/CCU715087-03-01) and National Institutes of Health/NIAID (grant 5K23AI050 585-02; to D.K.W.).

\section{REFERENCES}

1. Ibelings MM, Bruining HA. Methicillin-resistant Staphylococcus aureus: acquisition and risk of death in patients in the intensive care unit. Eur J Surg 1998; 164:411-418.

$\rightarrow$ 2. National Nosocomial Infections Surveillance (NNIS) System Report, data summary from January 1992 through June 2004, issued October 2004. Am J Infect Control 2004; 32:470-485.

$\rightarrow$ 3. Tiemersma EW, Bronzwaer SL, Lyytikainen O, et al. Methicillin-resistant Staphylococcus aureus in Europe, 1999-2002. Emerg Infect Dis 2004; 10: 1627-1634.

$\rightarrow$ 4. Corbella X, Dominguez MA, Pujol M, et al. Staphylococcus aureus nasal carriage as a marker for subsequent staphylococcal infections in intensive care unit patients. Eur J Clin Microbiol Infect Dis 1997; 16:351-357.

$\rightarrow$ 5. Davis KA, Stewart JJ, Crouch HK, Florez CE, Hospenthal DR. Methicillin-resistant Staphylococcus aureus (MRSA) nares colonization at hospital admission and its effect on subsequent MRSA infection. Clin Infect Dis 2004; 39:776-782.

$\rightarrow$ 6. Mest DR, Wong DH, Shimoda KJ, Mulligan ME, Wilson SE. Nasal colonization with methicillin-resistant Staphylococcus aureus on admission to the surgical intensive care unit increases the risk of infection. Anesth Analg 1994; 78:644-650.

$\rightarrow$ 7. Cosgrove SE, Sakoulas G, Perencevich EN, Schwaber MJ, Karchmer AW, Carmeli Y. Comparison of mortality associated with methicillin-resistant and methicillin-susceptible Staphylococcus aureus bacteremia: a metaanalysis. Clin Infect Dis 2003; 36:53-59.

8. Blot S, Vandewoude K, Hoste E, Colardyn F. Outcome and attributable mortality in critically Ill patients with bacteremia involving methicillinsusceptible and methicillin-resistant Staphylococcus aureus. Arch Intern Med 2002; 162:2229-2235.

$\rightarrow$ 9. Engemann JJ, Carmeli Y, Cosgrove SE, et al. Adverse clinical and economic outcomes attributable to methicillin resistance among patients with Staphylococcus aureus surgical site infection. Clin Infect Dis 2003; 36:592-598.

$\rightarrow$ 10. Jernigan JA, Titus MG, Groschel DH, Getchell-White S, Farr BM. Effectiveness of contact isolation during a hospital outbreak of methicillinresistant Staphylococcus aureus. Am J Epidemiol 1996; 143:496-504.

11. Harbarth S, Martin Y, Rohner P, Henry N, Auckenthaler R, Pittet D. Effect of delayed infection control measures on a hospital outbreak of methicillin-resistant Staphylococcus aureus. J Hosp Infect 2000; 46:43-49.

12. Girou E, Pujade G, Legrand P, Cizeau F, Brun-Buisson C. Selective screening of carriers for control of methicillin-resistant Staphylococcus aureus (MRSA) in high-risk hospital areas with a high level of endemic MRSA. Clin Infect Dis 1998; 27:543-550.

$\rightarrow$ 13. Merrer J, Santoli F, Appere-De Vecchi C, Tran B, De Jonghe B, Outin H. "Colonization pressure" and risk of acquisition of methicillin-resistant Staphylococcus aureus in a medical intensive care unit. Infect Control Hosp Epidemiol 2000; 21:718-723.

$\rightarrow$ 14. Marshall C, Harrington G, Wolfe R, Fairley C. Acquisition of methicillinresistant Staphylococcus aureus in a large intensive care unit. Infect Control Hosp Epidemiol 2003; 24:322-326.

$\rightarrow$ 15. Chaix C, Durand-Zaleski I, Alberti C, Brun-Buisson C. Control of endemic methicillin-resistant Staphylococcus aureus: a cost-benefit analysis in an intensive care unit. JAMA 1999; 282:1745-1751.

$\rightarrow$ 16. Girou E, Azar J, Wolkenstein P, Cizeau F, Brun-Buisson C, Roujeau JC. Comparison of systematic versus selective screening for methicillinresistant Staphylococcus aureus carriage in a high-risk dermatology ward. Infect Control Hosp Epidemiol 2000; 21:583-587.

17. Garner JS, Jarvis WR, Emori TG, Horan TC, Hughes JM. CDC definitions for nosocomial infections, 1988. Am J Infect Control 1988; 16:128-140.

18. Hennekens CH, Buring JE. Screening. In: Mayrent SL, ed. Epidemiology in Medicine. 1st ed. Boston: Little, Brown and Company; 1987:327-347.

19. Lucet J, Chevret S, Durand-Zaleski I, Chastang C, Regnier B. Prevalence and risk factors for carriage of methicillin-resistant Staphylococcus aureus at admission to the intensive care unit. Arch Intern Med 2003; 163:181-188.

20. Jernigan J, Pullen A, Flowers L, Bell M, Jarvis W. Prevalence of and risk factors for colonization with methicillin-resistant Staphylococcus aureus 
at the time of hospital admission. Infect Control Hosp Epidemiol 2003; 24:409-414.

$\rightarrow$ 21. Coello R, Jimenez J, Garcia M, et al. Prospective study of infection, colonization and carriage of methicillin-resistant Staphylococcus aureus in an outbreak affecting 990 patients. Eur J Clin Microbiol Infect Dis 1994; 13:74-81.

22. Boyce J, Havill N, Kohan C, Dumigan D, Ligi C. Do infection control measures work for methicillin-resistant Staphylococcus aureus? Infect Control Hosp Epidemiol 2004; 25:395-401.

23. Scanvic A, Denic L, Gaillon S, Giry P, Andremont A, Lucet JC. Duration of colonization by methicillin-resistant Staphylococcus aureus after hospital discharge and risk factors for prolonged carriage. Clin Infect Dis 2001; 32:1393-1398.

$\rightarrow$ 24. Sanford MD, Widmer AF, Bale MJ, Jones RN, Wenzel RP. Efficient detection and long-term persistence of the carriage of methicillin-resistant Staphylococcus aureus. Clin Infect Dis 1994; 19:1123-1128.

25. Bradley SF, Terpenning MS, Ramsey MA, et al. Methicillin-resistant Staphylococcus aureus: colonization and infection in a long-term care facility. Ann Intern Med 1991; 115:417-422.

26. Muder RR, Brennen C, Wagener MM, et al. Methicillin-resistant staphylococcal colonization and infection in a long-term care facility. Ann Intern Med 1991; 114:107-112.

$\rightarrow$ 27. Boyce JM. MRSA patients: proven methods to treat colonization and infection. J Hosp Infect 2001; 48(Suppl A):S9-S14.
28. Ma XX, Ito T, Tiensasitorn C, et al. Novel type of staphylococcal cassette chromosome mec identified in community-acquired methicillin-resistant Staphylococcus aureus strains. Antimicrob Agents Chemother 2002; 46: 1147-1152.

29. Troillet N, Carmeli Y, Samore MH, et al. Carriage of methicillin-resistant Staphylococcus aureus at hospital admission. Infect Control Hosp Epidemiol 1998; 19:181-185.

30. Wilson R. Bacteria, antibiotics and COPD. Eur Respir J 2001; 17:995-1007.

$\rightarrow$ 31. Lucet JC, Paoletti X, Lolom I, et al. Successful long-term program for controlling methicillin-resistant Staphylococcus aureus in intensive care units. Intensive Care Med 2005; 31:1051-1057.

32. Grundmann H, Hori S, Winter B, Tami A, Austin DJ. Risk factors for the transmission of methicillin-resistant Staphylococcus aureus in an adult intensive care unit: fitting a model to the data. J Infect Dis 2002; 185: 481-488.

$\rightarrow$ 33. Roghmann MC, Siddiqui A, Plaisance K, Standiford H. MRSA colonization and the risk of MRSA bacteraemia in hospitalized patients with chronic ulcers. J Hosp Infect 2001; 47:98-103.

$\rightarrow$ 34. Thurn J, Crossley K, Gerdts A, Maki M, Johnson J. Enteral hyperalimentation as a source of nosocomial infection. J Hosp Infect 1990; 15: 203-217.

$\rightarrow$ 35. Dziekan G, Hahn A, Thune K, et al. Methicillin-resistant Staphylococcus aureus in a teaching hospital: investigation of nosocomial transmission using a matched case-control study. J Hosp Infect 2000; 46:263-270.

Note Added in Proof. During the interval between publication of this article online and publication in print, errors were noted in tables 2 and 4. The corrected tables are given in an erratum in this issue of the journal (pages 1140-1141). 